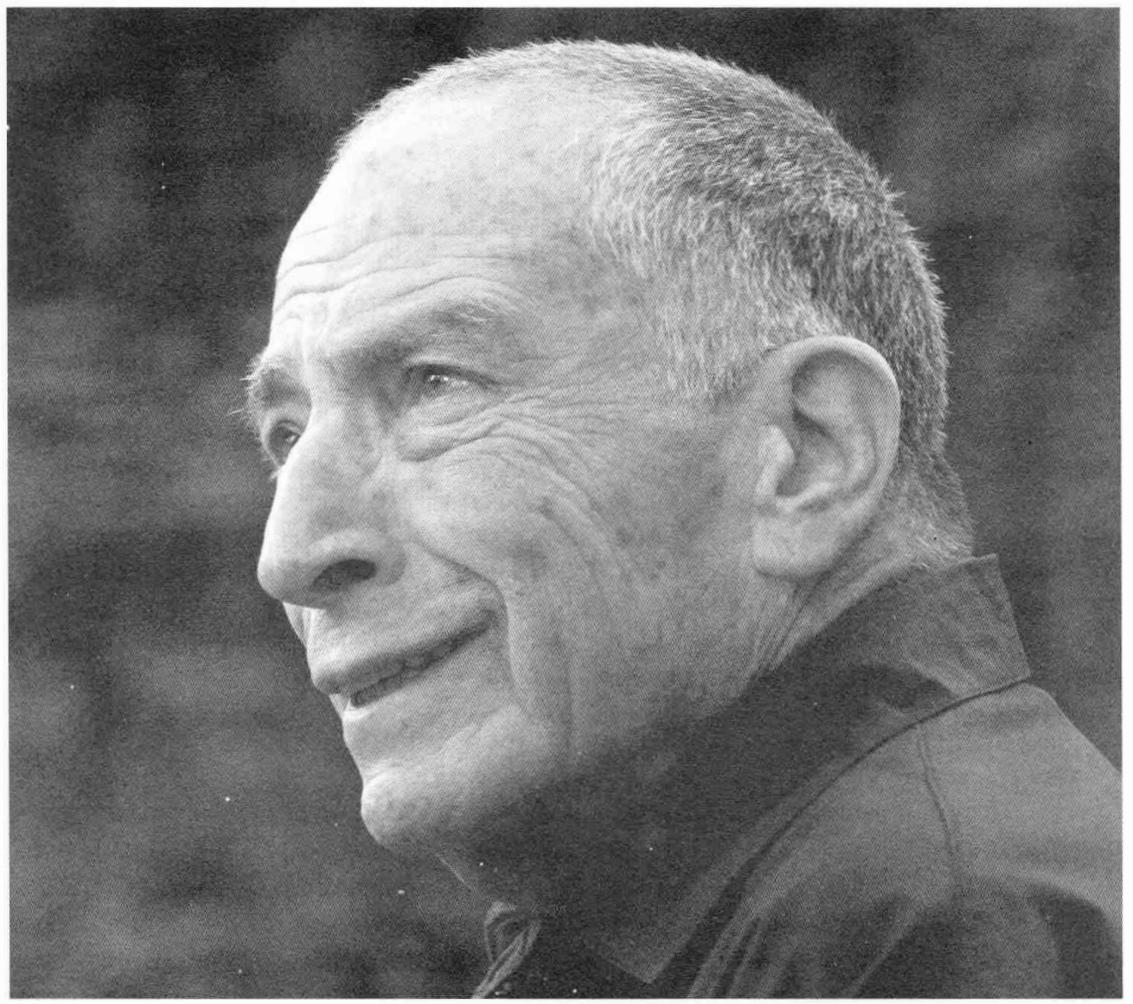




\section{Angeles Mosquera}

Licenciada en Humanidades por la Universitat Jaume I. Su línea de investigación se centró en el estudio del primer parlamentarismo mexicano, tema sobre el que trabajó en la tesis de licenciatura. Actualmente investiga sobre la institución del Consejo de Indias en el reinado de Fernando VII y la problemática americana del momento para la realización de la tesis de doctorado.

\section{Resumen}

En 1821 México obtuvo su independencia de la metrópoli y comenzó así su andadura hacia la construcción de un Estado basado, de acuerdo con el Plan de Iguala y los Tratados de Córdoba, en una monarquía parlamentaria que definió la división de poderes pero sin un monarca que ocupara el trono de momento. La unión de los diferentes sectores sociales alrededor del Plan de Iguala pronto se truncó al surgir diferencias entre ellos. Estas diferencias se plasmaron en algunos de los debates surgidos en el seno del primer Parlamento mexicano. Las discusiones en torno a la fuerza armada que quería implantarse en el país dieron lugar a uno de los debates en donde se hizo más evidente la pugna por el poder entre las diversas facciones políticas, conflicto que acabaría con la disolución del Congreso decretada por el entonces emperador Agustín de Iturbide.

Palabras clave:

Imperio, México, constitucionalismo, ejército, milicia, Iturbide.

\section{Abstract}

In 1821, Mexico obtained its independence from the metropolis, thereby beginning its journey towards the construction of a state based, according to the Plan of Iguala and the Córdoba Treaties on a parliamentary monarchy that defined the division of powers but without a monarch to occupy the throne at that moment. The union of the various social sectors around the Plan of Ayala was shattered as differences between them began to emerge. These differences were reflected in some of the debates that arose in the first Mexican parliament. The discussions on the armed forces that sought to establish itself in the country gave rise to one of the debates that most clearly evinced the struggle for power between the various political factions, a conflict that would end with the dissolution of Congress decreed by the then emperor Agustín de Iturbide.

Key words:

Empire, Mexico, constitutionalism, army, militia, Iturbide.

Fecha de recepción: octubre de 2004

Fecha de aceptación: abril de 2005 


\title{
Ejército y milicia cívica. Fuerzas armadas y pugna de poderes en el primer parlamentarismo mexicano, 1821-1824
}

\author{
Ángeles Mosquera*
}

L

os primeros años de la independencia de México se caracterizaron por una inestabilidad política y la búsqueda de un sistema de gobierno adecuado para implantar en la naciente nación mexicana. El Plan de Iguala consiguió la unidad necesaria entre las diversas facciones para alcanzar la anhelada libertad, pero una vez conseguida, los diferentes intereses no tardaron en enfrentarse. La relación entre Agustín de Iturbide y el primer Congreso Constituyente fue complicada desde un principio, dando lugar a numerosos enfrentamientos que acabaron por desgastar a ambos. La interpretación divergente de la soberanía popular provocó una serie de discrepancias y elevó la tensión. Agustín de Iturbide asumió que representaba la voluntad popular debido a la adhesión unánime al Plan de Iguala; en la práctica, suponía que el Congreso no era más que un resultado de sus actos. ${ }^{1}$ En

* El presente texto fue elaborado en el marco de mi tesis de licenciatura, "El primer parlamentarismo mexicano, 1821-1822", preparado en la Universitat Jaume I (Castellón) entre 1999 y enero de 2001. En su versión actual se ha beneficiado de la lectura y observaciones de los profesores José A. Piqueras y Vicent Sanz, así como de las indicaciones de los dictaminadores anónimos de la revista Secuencia.

'Sordo, "Congreso", 2003, p. 119. cambio, el Congreso se adjudicó la soberanía el primer día de su instalación reuniendo los tres poderes en su seno, pero delegando interinamente dos de ellos por el bien de la nación. ${ }^{2}$ Además de estas diferencias el Congreso se encontró muy dividido internamente, en el que destacaban tres partidos o facciones: borbonistas, iturbidistas y republicanos. Uno de ellos, el primero y contrario a la figura de Iturbide, dominó el Congreso en su primera etapa, convirtiendo este órgano en un instrumento de enfrentamiento con "el libertador". ${ }^{3}$ Las discrepancias y desconfianza entre ambos tuvo importantes consecuencias en el desarrollo político del país y en las votaciones de los negocios debatidos en el seno del Congreso.

El presente artículo pretende dar a conocer hasta qué punto las relaciones y el conflicto entre los diferentes actores políticos influyó en la organización de las fuerzas armadas del naciente Estado, fundamentalmente a través de los primeros e interesantes debates parlamentarios del primer Congreso Constituyente.

${ }^{2}$ Actas, 1980, t. Il, sesión del 24 de febrero de 1822, p. 8.

${ }^{3}$ Alamán, Historia, 1942, t. v, p. 546. 
FUERZAS ARMADAS E INDEPENDENCIA

Durante la guerra de independencia que Nueva España libró contra la metrópoli fueron diversas las fuerzas armadas establecidas por los bandos realista e insurgente para conseguir la victoria. Desde el lado realista, el ejército permanente y la milicia provincial constituyeron la fuerza fundamental de la que dispuso el virrey para hacer frente a las insurrecciones surgidas desde 1810 hasta la llegada de la independencia, en 1821. El ejército profesional era el resultado de las reformas borbónicas aplicadas en América para mejorar la defensa del territorio contra los diversos peligros que pudieran surgir. La práctica militar había demostrado una importante vulnerabilidad frente a las tropas inglesas, cuando éstas tomaron la ciudad de $\mathrm{La} \mathrm{Ha-}$ bana en $1762 .{ }^{4}$ Hasta ese momento, el sistema defensivo americano se había basado en la existencia de una poderosa armada, capaz de hacer frente a los piratas o a cualquier potencia que quisiera obtener las mercancías y productos originarios de las provincias de ultramar, y la fortificación de los puertos más destacados susceptibles de ser atacados. Mientras tanto, cualquier problema de orden interno era solucionado armando y organizando en momentos puntuales a la población en milicias.

La toma de La Habana convenció a la monarquía de la necesidad de emprender un arreglo del ejército profesional. Al tiempo que lo dotó de una mayor presencia en América, lo convirtió en baluarte de la corona y en el instrumento para apli-

${ }^{4}$ Archer, Ejército, 1983. Archer demuestra el temor a las invasiones que sufría el ejército en América a finales del siglo xviII. car las reformas borbónicas a todos los niveles. ${ }^{5} \mathrm{La}$ principal prioridad en la reorganización del ejército fue la defensa externa de las provincias de ultramar más que pensar en los desórdenes internos, para el cual se promovió el establecimiento de milicias. Por primera vez la defensa de las provincias dependerá de sus habitantes. La imposibilidad de enviar contingente español ante los numerosos conflictos en los que estaba involucrada la corona facilitó este plan. ${ }^{6}$

La reforma se diseñó y se planteó partiendo de la base social existente en las ciudades españolas, sin tener presentes las circunstancias particulares de las colonias, por lo que surgieron serias dificultades al aplicarse en los territorios de ultramar. En el sorteo de las levas entraban, para formar parte del grueso de la tropa, todos los hombres solteros de entre 16 y 36 años, sin impedimento físico que estuvieran dedicados al artesanado, al pastoreo, los jornaleros o cualquier empleo similar, siendo el grado de sargento el último al que podían aspirar. Cabe destacar en relación con América que quedaron excluidos del servicio de armas los indios, negros y castas por ser considerados moralmente inapropiados para efectuar dicha tarea. Resultado de esto fue que, en la práctica, las ordenanzas exceptuaron a la mayoría de la población americana para el servicio, lo que dificultó enormemente el reclutamiento de un ejército en estos territorios. A consecuencia de ello, tuvo que aplicarse una serie de excepciones que permitían el reclutamiento de las castas. ${ }^{7}$ Los nobles, los grandes propietarios, los notables o los

\footnotetext{
${ }^{5}$ Marchena, Ejército, 1992, pp. 135-139.

${ }^{6}$ Ortiz, Guerra, 1997, pp. 54-55.

7 Archer, Ejército, 1983, pp. 29-32.
} 
trabajadores muy cualificados también quedaban exentos del servicio militar, sin embargo, podían ingresar de modo voluntario ocupando los puestos de la oficialidad. No obstante, los cargos más destacados eran designados desde la Península y, normalmente, ocupados por algún peninsular; de ese modo el rey se aseguraba el control de la fuerza armada mientras la elite criolla quedaba excluida, con el consecuente descontento de este grupo social. ${ }^{8}$ En general, las ordenanzas se caracterizaron por trasladar al ejército la jerarquización presente en la sociedad, donde la ocupación de los cargos dependió de la existencia de privilegios y donde la ruptura de esa estructura supuso una práctica casi imposible de lograr.

El caso de las milicias fue diferente y las elites criollas pudieron participar en la formación de la fuerza armada que iba a proteger el orden interno. Las milicias no eran cuerpos permanentes, sino que eran llamadas en momentos puntuales. Eso quiere decir que su establecimiento no supuso la militarización de la sociedad. La práctica habitual fue organizar un plan provisional que únicamente podía ponerse en marcha en caso de peligro real. ${ }^{9}$ Para formar parte de la milicia debían cumplirse unos requisitos, principalmente económicos, por lo que ésta se formó sobre un sector intermedio de la población. Los nobles, los funcionarios y los grupos sociales más altos quedaron excluidos del servicio aunque podían ingresar en los puestos de la oficialidad. En un principio se reservaron los cargos más importantes

${ }^{8}$ Ortiz, Guerra, 1997, p. 56. Sobre el ejército borbónico al final del antiguo régimen, véase Blanco, Rey, 1988.

${ }^{9}$ Marchena, Ejercito, 1992. para los oficiales europeos, lo que llevó a un enfrentamiento con las elites locales. Las reformas introducidas por el virrey $\mathrm{Ta}$ lamanca y Branciforte permitieron a estas elites hacerse cargo de la capacidad de organización de las milicias. La venta de los puestos más destacados de la oficialidad, característico del periodo, hizo que aquéllas se involucraran con más facilidad. Como en el ejército, los jefes y oficiales de las milicias disfrutaron del privilegio de fuero militar.

A pesar de las reformas, este sistema defensivo resultó insuficiente a la hora de combatir la insurrección de Hidalgo o Morelos. La necesidad de aumentar el contingente y movilizar a la población hacia la causa realista, junto con la imposibilidad de incrementar el gasto para poner en práctica dicha medida, llevó al gobierno virteinal a introducir novedosos cambios en las ordenanzas de las milicias ampliando la base social que podía formar parte de ella. En 1811 Félix María Calleja aprobó un nuevo reglamento que exhortaba a la población civil a incorporarse a las milicias para luchar en la defensa de sus ciudades, pueblos o villas y contra el movimiento insurgente. Todas las poblaciones tenían la obligación de establecer una milicia para su propia defensa, pudiendo formar parte de ella cualquier vecino honrado y, a diferencia de la estricta jerarquización del ejército, todos debían cumplir con las mismas obligaciones eligiendo los propios milicianos a sus oficiales por votación. Las milicias llegaron a adquirir un destacado papel en la lucha contra la insurgencia. La pacificación del territorio en 1818 encaminó al virrey Apodaca a probar la desmovilización de muchas de las milicias establecidas, desmilitarizando a la población por temor a un 
levantamiento. Iturbide consiguió reunir en el Plan de Iguala al ejército permanente y a las elites locales que movilizaron a las milicias para alcanzar la independencia. ${ }^{10}$

Las fuerzas armadas del movimiento insurgente se caracterizaron, en un primer momento, por su falta de disciplina y general desorden. El grueso de la tropa estaba formado por las clases sociales más empobrecidas. Hidalgo tratô de organizar su ejército y trasladar a él las ordenanzas del ejército permanente, pero la falta de disciplina y los pillajes ejercidos por la tropa después de cada ataque provocó un gran temor entre la población más pudiente. Derrocado el levantamiento, los siguientes líderes insurgentes aplicaron unas ordenanzas más estrictas, impidiendo estos desórdenes públicos.

La mayoría de estas fuerzas militares, heterogéneas en su composición y origen, fueron reunidas en un único ejército, conocido como Trigarante, bajo las órdenes de Agustín de Iturbide. Su ejército quedó compuesto por europeos y americanos, algunos procedentes del ejército profesional, otros de las milicias y de las compañías de patriotas. A éstos se adhirieron los combatientes del bando insurgente, destacando la fuerza liderada por Vicente Guerrero. La unidad necesaria para llevar a cabo el nuevo planteamiento político y social se consiguió tras la aceptación por parte de todos del Plan de Iguala en septiembre de 1821, ratificado posteriormente en los Tratados de Córdoba en octubre del mismo año por el representante del gobierno español, Juan de O'Donojú. De este modo, fue reconocida la independencia de Nueva España dando lugar al naciente imperio mexicano. El nuevo Estado nació

${ }^{10}$ Ortiz, Guerra, 1997, pp. 140-141. bajo la forma de una monarquía constitucional, con el respectivo llamamiento al rey Fernando VII o, en su lugar, a un familiar cercano de la misma casa reinante, bajo la Constitución de 1812, declarada vigente provisionalmente hasta la promulgación de una constitución propia.

El primer paso para la formación del nuevo gobierno fue el establecimiento de una Suprema Junta Gubernativa, cuyos miembros fueron elegidos por Agustín de Iturbide. Su principal labor consistió en la redacción de una base de convocatoria bajo la cual se llevaría a cabo la elección de los diputados del Congreso Constituyente. La discusión del proyecto de convocatoria puso de manifiesto más de una discrepancia entre Iturbide, que ahora formaba parte de la Regencia, y los miembros de la Junta. ${ }^{11}$ Superadas las diferencias, la convocatoria resultante fue aprobada sobre la base de una representación estamental y no proporcional, lo que provocó descontento en algunas de las provincias del imperio, que no se verán representadas en el Congreso nacional. Como tampoco agradó plenamente a Iturbide, quien trató de intervenir en el proyecto de convocatoria. Iturbide insistió en la formación de dos cámaras en lugar de una sola, lo que fue aprobado por los diputados de la Junta aunque posteriormente no llegó a ponerse en práctica. Al parecer, y de acuerdo con las actas, el primer día de instalación del Congreso los diputados fueron reunidos en una única sala, al no encontrarse otra que estuviera habilitada convenientemente. Nunca más volvió a hablarse del

${ }^{11}$ El mismo Agustín de Iturbide hace referencia a estos acontecimientos en sus "Memorias que escribió en Liorna D. Agustín de Iturbide" en Cuevas, Libertador, 1947, pp. 398-425. 
tema. ${ }^{12} \mathrm{El}$ Congreso Constituyente quedó reunido en una sola sala como se había planteado inicialmente. El malestar de Iturbide por lo sucedido y por el nuevo legislativo quedó reflejado en sus últimos escritos. ${ }^{13}$

\section{EL EJÉRCITO PERMANENTE (TRIGARANTE)}

En la creación del nuevo Estado mexicano, la misma existencia y subsistencia del ejército permanente se cuestionó en el Congreso Constituyente, lo que ocasionó más de un enfrentamiento directo con la Regencia. Agustín de Iturbide quiso desde el primer día recompensar al Ejército Trigarante por el apoyo prestado a la causa y mantenerlo como un firme aliado que apoyara sus decisiones, pero era una alianza frágil que había que atender y fomentar. ${ }^{14}$ El respaldo del ejército era fundamental dadas las circunstancias tan peculiares por las cuales México había accedido a la independencia, con una coalición de sectores tan diversos, y suponía en la práctica disponer del poder, garantizando la participación en la política del país. Para Iturbide ese ejército era su fuerza y la mejor defensa de su proyecto político, a través del cual esperaba ponerlo en marcha. Pero resultó difícil mantener el apoyo de la tropa y la

${ }^{12}$ Actas, 1980, t. II. En las primeras páginas se hace referencia al primer día de constitución del Congreso y al incidente presentado.

13 "Memorias que escribió en Liorna D. Agustín de Iturbide" en Cuevas, Libertador, 1947, pp. 398-425.

${ }^{14}$ Timothy E. Anna muestra la importancia del apoyo del ejército para Iturbide y su necesidad de recompensar al ejército para conservar esa alianza. Anna, Imperio, 1991, p. 298. disciplina dada la situación en la que se encontró el país una vez alcanzada la independencia. A instancias de Iturbide, los militares mantuvieron el privilegio del fuero militar pero su situación, en general, se deterioró con respecto a la etapa anterior debido en gran parte a la escasez de fondos de la Hacienda nacional, incapaz de hacer frente al pago de los sueldos. Al mismo tiempo, la imposibilidad de conceder los premios prometidos a los soldados, como la concesión de tierras, impidió que muchos de éstos pudieran reincorporarse a la vida civil dignamente.

El Congreso, en cambio, entendió que alcanzada la independencia era preciso proceder a la realización de cambios necesarios para dar lugar a un nuevo ejército, defensor de los principios asentados por aquél. Los debates surgidos en torno a las fuerzas armadas dieron a conocer abiertamente los diferentes intereses de los grupos surgidos en el seno del Congreso y los de Iturbide. Las discrepancias entre ambos cuerpos sobre el futuro del país y la elección del sistema de gobierno más adecuado se trasladó a cada uno de los temas más relevantes debatidos por la Cámara. Esto explica, en muchas ocasiones, el rechazo del Congreso a algunas de las propuestas presentadas por Iturbide y viceversa. La existencia de partidos o facciones explica las discrepancias y enfrentamientos entre los diputados, o aquéllas por éstas, y del Congreso con el ejecutivo. Los borbonistas, grupo predominante en el Parlamento, convirtieron a éste en el principal instrumento de oposición a Iturbide y a sus propuestas. Pero el faccionalismo no se limitó a las grandes corrientes políticas, pues los diputados representaron los intereses de sus provincias que llegaron a ver con desconfianza algunas disposiciones 
adoptadas por unos y otros. Los republicanos, que en este momento carecían de fuerza suficiente, mostraron una política vacilante, haciendo causa común a menudo con los borbonistas y en ocasiones con los iturbidistas, dependiendo del tema en cuestión. Esta actitud evolucionó hacia una postura de reafirmación del republicanismo y de oposición a Iturbide, sobre todo cuando éste adoptó medidas de persecución contra los diputados y aprobó la disolución del Congreso. La llegada de Servando Teresa de Mier al Congreso reforzó este grupo. Mientras tanto, los iturbidistas, incapaces de dominar el Congreso, fueron decantándose por la coronación de Iturbide. Su definitiva investidura el 19 de mayo de 1822 volvió a perfilar las alineaciones de los partidos, uniendo a borbonistas y republicanos en una causa común, como fue precipitar la caída del emperador. ${ }^{1.5}$

Junto a las discrepancias internas, la oposición manifiesta entre el Congreso e Iturbide dificultó un acuerdo en temas tan sustanciales para el país y el Estado como la conformación de las fuerzas armadas. La desconfianza mutua llevó a un posicionamiento imposible de conciliar. Desde el día de su instalación, el ejército permanente fue un tema constante de debate en las sesiones del Congreso, primordialmente por cuestiones económicas. Los soldados que no recibían sus sueldos y la situación general de las tropas se tornó preocupante ante la carencia de medios con que auxiliarla. En diversas ocasiones Iturbide intentó remediar la escasez de fondos recurriendo a la Junta, primero, y posteriormente al Congreso, con el objetivo de solicitar ciertas cantidades de di-

\footnotetext{
${ }^{15}$ Sordo, "Congreso", 2003, pp. 118-119.
}

nero con el cual poder encarar los pagos de la tropa. Sin embargo, apenas obtuvo respuesta y el impago al ejército siguió siendo continuo. ${ }^{16}$ Pasados unos meses desde la independencia, el país era incapaz de afrontar el problema, como mostró el informe que el 31 de enero de 1822 el ministro de Hacienda dirigió a la Junta Gubernativa comunicándole el déficit existente en relación con el desembolso que debía realizarse a favor del ejército. Al día siguiente Agustín de Iturbide, que entonces ocupaba la Regencia del país, asistió a la sesión para poner en conocimiento de los miembros de la Junta este hecho y requerir que se tratara el asunto en sesión permanente, lo cual se aceptó. ${ }^{17}$ Las cantidades destinadas no debieron ser suficientes, puesto que la situación apenas mejoró y, dos meses después, un oficio del mismo ministro informó de la necesidad de 89.350 pesos para los gastos de algunas tesorerías generales y las del ejército. ${ }^{18}$

No transcurrió mucho tiempo antes de que las quejas de la Regencia volvieran a recordar a los integrantes de la Junta las penurias que sufría la tropa, como la posibilidad de que la caballada muriera por falta de piensos, e informó de las deserciones que se estaban produciendo a causa del hambre. ${ }^{19}$ De nuevo la Regencia soli-

${ }^{16}$ Anna, Imperio, 1991 , pp. 74-80.

${ }^{17}$ Actas, 1980, t. I, sesión del 31 de enero a 1 de febrero de 1822, pp. 271-274.

${ }^{18} \mathrm{Ibid}$., t. II, sesión del 2 de marzo de 1822 , p. 34. El Congreso pide al ministro que antes de tomar alguna medida envíe un informe sobre el estado de Hacienda. El informe llegó en la sesión del 4 de marzo de 1822, donde se proponía una contribución anual de cinco pesos para este déficit presupuestario, pp. 38-39.

${ }^{19}$ Ibid., sesión del 13 y 18 de marzo de 1822 , pp. 69 y 84 . En esta última sesión el diputado Herrera 
citó respuestas inmediatas para zanjar el problema. Es evidente que, por su insistencia, esta situación preocupaba de un modo especial al ejecutivo, no así a la Junta, que delegaba en el Congreso la adopción de las medidas adecuadas. El regente y general del Ejército Trigarante percibía cómo la situación económica de su principal aliado empeoraba hasta llegar a un grado lamentable, muy a pesar de las promesas realizadas.

En dos ocasiones más, y antes de la finalización del mes de marzo de 1822, la Regencia volvió a remitir, esta vez al Congreso ya constituido, informes sobre la triste situación que atravesaba la tropa. ${ }^{20}$ En el último de ellos el ejecutivo propuso el desvío de 1500000 pesos, destinados inicialmente a la renta del tabaco. En el informe se acusó al Congreso de ignorar este grave asunto, lo que provocó la crispación de algunos diputados que acusaron a la Regencia de no saber aplicar las providencias dictadas y de perder el tiempo en continuas consultas. La comunicación entre ambos cuerpos continuaba deteriorándose. Al celo de Iturbide por solucionar este problema se unió el poco interés de los diputados por arreglarlo bajo el discurso de la existencia de problemas de mayor urgencia. De hecho, y a pesar de la complicada situación del ejército y de la necesidad de arreglar sus estatutos, los diputados del Congreso prefirieron discu-

pregunta por qué la tropa está toda en la capital y no defendiendo los puertos, donde se le pagaba con normalidad.

${ }^{20} \mathrm{Ibid}$., sesiones del 20 y 23 de marzo de 1822 . En la última sesión la Regencia señala las dificultades de algunas medidas del Congreso, ya que no había compradores de las temporalidades puestas en venta, pp. 103-105. tir previamente el decreto de la milicia cívica para ponerlo en práctica lo antes posible. El debate, que más adelante mostraremos, se llevó a cabo al plantearse la necesidad de crear una fuerza armada eficiente con el propósito de defender el país y el Estado constitucional. Las diferencias y la aparente apatía del Congreso ante la cuestión militar revelaba un meditado plan de los sectores antiiturbidistas destinado a impedir que el presidente de la Regencia concentrara excesivo poder, a la vez que anunciaba el propósito de disponer de una fuerza al servicio de su política, en caso de que ésta llegara a contraponerse a la del ejecutivo. Ahora bien, ¿se trataba únicamente de un posicionamiento político sobre la organización del Estado soberano y la distribución de poderes, o las diferencias y las tensiones sobre las fuerzas armadas encerraba, además, propuestas distintas de predominio social en la nueva nación? Los grupos e intereses, diversos y dispersos, agrupados en el momento del Plan de Iguala y confirmados por el Tratado de Córdoba, que habían dejado inermes a los realistas y a los intereses cobijados bajo el amparo del antiguo régimen español, debían moverse con extraordinaria rapidez en el nuevo sistema, asociándose en ocasiones con los antagonistas tradicionales para ponerse a salvo y estar en condiciones de ocupar una posición privilegiada en la situación que estaba creándose, que todavía no podía darse por definida, como demostrarían los acontecimientos de los siguientes años. Por eso las controversias que tienen lugar sobre la organización del instrumento coercitivo del Estado por antonomasia, su concepción funcional y su dependencia orgánica se reveló como una cuestión de absoluta trascendencia. Mientras Iturbide trató de dar 
cabida al Trigarante dentro del nuevo orden político, el Congreso optó primero por reformar las milicias para posteriormente modificar los estatutos del ejército. Esto sugiere que la Cámara intentó crear una fuerza armada leal a sus intereses, con capacidad de sostener sus decisiones. El debate sobre la milicia vigorizó el conflicto existente entre ambos cuerpos, el legislativo y el ejecutivo, y supuso medir la fuerza y los diferentes intereses reflejados, en esta ocasión, en la fuerza armada que debía sostenerlos. $^{21}$

Las medidas decretadas para poner fin a la estrechez sufrida por las tropas fueron, en la mayoría de los casos, una solución a corto plazo, puesto que no se hicieron grandes cambios en la Hacienda, ni en lo referente a la creación de impuestos y recaudación de los mismos, ni en su administración. Si los fondos recaudados eran insuficientes para cubrir todos los gastos del Estado, cabía añadir la existencia de una importante deuda externa mientras que los distintos ramos de la economía resultaban escasamente rentables debido a la crisis que atravesaban como consecuencia del deterioro producido en los años de guerra. ${ }^{22}$ Los diputados optaron por la aprobación de medidas rápidas como el traslado a la capital de forma inmediata del caudal de las Cajas de provincias como Veracruz, Oaxaca o Guadalajara. ${ }^{23}$ Esta

${ }^{21}$ Con más extensión en Mosquera, Primer, 2001.

${ }^{22}$ Para la situación de la Hacienda, véase la introducción al tema de Jáuregui, "Fundamentos", 1993, pp. 378-383. Los empréstitos forzosos de Iturbide, en Valle, "Empréstitos", 1998, en especial pp. 66-72; la situación financiera del momento, en Ludlow, "Elites", 1998, en especial pp. 79-114. Véase también la síntesis de Zoraida, "Primeros", 1.987, pp. 737-818.

${ }^{23}$ Actas, 1980, t. Il, sesión del 19 de abril de 1822, p. 61. providencia motivó reacciones populares en las provincias que advirtieron cómo su dinero era destinado a las arcas del Estado para el pago de un ejército concentrado en la capital mientras, en el caso de Veracruz, el Castillo de San Juan de Ulúa permanecía bajo dominio español. Ésta fue una de las causas por las que las provincias se negaron a informar al Estado sobre sus Cajas, o no notificaron el contenido real de las mismas, comó refleja la carencia de información de la que dispusieron los diputados sobre la existencia de esos fondos.

Otras medidas aprobadas para subsanar el déficit fueron la aprobación de préstamos voluntarios a las provincias y el restablecimiento de determinadas contribuciones suprimidas hacía apenas unos meses, ambas bastante impopulares, especialmente la primera. ${ }^{24}$ En el momento de la independencia la Junta Gubernativa abolió impuestos que consideró injustos, como las alcabalas o los tributos personales, pero no los sustituyó por otros más acordes con un Estado liberal, lo que ocasionó el vacío de las arcas, por considerar que correspondía al futuro Congreso la facultad de aprobar nuevos gravámenes. Ahora bien, en 1822 se discutieron propuestas para corregir la situación, por ejemplo, la defendida por el diputado $\mathrm{Hi}$ pólito Odoardo, quien en la sesión del 19 de abril planteó la creación de impuestos de acuerdo con las posibilidades de la población; sin embargo, el Congreso no llegó a aprobar nada definitivo en relación

${ }^{24}$ El préstamo voluntario fue aprobado en la sesión del 15 de abril de 1822 . La idea era dar a conocer las necesidades del erario, y concretamente del ejército entre la población, sobre todo de la pudiente. A cambio de dinero prestado recibirían billetes firmados de diversos valores, ibid., pp. 32-34. 
con el tema. En cambio, sí llegó a aprobarse un proyecto de arancel común para unificar el sistema impositivo sobre el comercio exterior. La implantación de nuevos impuestos era una medida muy impopular y la carencia de un ejército fuerte y disciplinado, que debía ser sufragado con el producto de la recaudación, tampoco permitió su imposición. El debate parlamentario acabó desviándose hacia el desconocimiento existente de la entrada y salida real de los fondos, en el que se denunciaba que el ministro de Hacienda, aunque insistía en pedir dinero para el pago del ejército, no informaba sobre las cuentas del Estado probablemente porque él mismo carecía de datos. ${ }^{25}$

Las quejas sobre la situación de la tropa continuaron siendo centro de atención en las siguientes sesiones. El diputado Agustín Paz intentó, en varias intervenciones, llamar la atención sobre el peligro que suponía un ejército hambriento y las consecuencias irreparables que los desórdenes podían ocasionar para la libertad del Estado ${ }^{26}$ Cabía la posibilidad, además, de que el Ejército Trigarante no sostuviera las decisiones de un Congreso incapaz de satisfacer y solucionar sus problemas más inmediatos. En la misma sesión del 19 de abril de 1822, el diputado J. Antonio de Andrade, militar e iturbidista, recordó al Congreso la importancia de auxiliar a la tropa, puesto que las decisiones de este órgano no podrían ser aplicadas si no eran sostenidas por los militares. Es incuestionable que el problema del ejército fue, para los parlamentarios, algo más que una cuestión de carencia de fondos: la perma-

${ }^{25}$ Ibid., sesión del 19 de abril de 1822, p. 62.

${ }^{26} \mathrm{Ibid}$., sesiones del 22 de marzo y 19 de abril de 1822 , p. 61 . nencia del orden social establecido y la continuidad del incipiente Estado soberano pasaban por conseguir y mantener su respaldo, o bien por implantar una fuerza leal. Al plantear el establecimiento de la milicia a mediados de abril, los diputados tenían en mente organizar una fuerza armada alternativa compuesta por civiles, que pudiera sostener y defender sus intereses, que dependería directamente del Congreso en contraposición a un ejército, no muy numeroso pero acantonado en la ciudad.

Mientras tanto, Agustín de Iturbicle trató de contentar a los militares mediante otras disposiciones como la entrega de premios a los "héroes" de la independencia y a los soldados de mayor valor, o aprobando la concesión de las pensiones a los familiares de los soldados muertos en acto de guerra. Desde un principio se propuso la creación de una orden militar, conocida como la Orden Imperial de Guadalupe, con el objetivo de "premiar el valor y las virtudes de aquellos que todo lo sacrificaron por elevar a la patria al alto rango que hoy obtienen, y que se dedicaron en lo sucesivo a contribuir a sus glorias y esplendor". ${ }^{27}$ El 21 de marzo de 1822 el Congreso aprobó el decreto sobre premios exclusivamente militares con el objetivo de "dar a las beneméritas tropas nacionales muestras del aprecio con que la patria mira los importantes servicios prestados por ellos a la santa causa de la libertad y emancipación de este imperio" 28 Se recompensaba así a los militares que parti-

27 Dublán y Lozano, Legislación, 1876. Decreto sobre establecimiento de la Orden Imperial Guadalupana, p. 595.

${ }^{28}$ Actas, 1980, t. II, sesión del 21 de marzo de 1822, pp. 93-95. 
ciparon en los años anteriores a la independencia, quedando excluidos los que colaboraron y lucharon en la conocida como primera época. Iturbide no aceptó reconocer a estos hombres como héroes, puesto que en esa etapa él luchó con el bando realista participando en la persecución de los primeros insurgentes. El Congreso así lo aceptó a pesar de la petición de algunos diputados marcadamente antiiturbidistas y republicanos, como Carlos María de Bustamante, quien lo había exigido. ${ }^{29}$

El decreto de premios militares precisó quiénes tenían derecho a percibirlos y cómo serían concedidos y aplicados. Se incluyó y reconoció la labor de las tropas de Vicente Guerrero y las del capitán general y jefe político de Nueva España, Juan de O'Donojú, y las convirtió en merecedoras de los premios por su pronta adhesión a la causa. Sin embargo, estas medidas no calmaron los ánimos del ejército. La falta de fondos impidió, entre otras cosas, el pago de las pensiones, por lo que el problema principal continuó siendo el económico. Pero amenazaba hacerse político...

Ante el permanente malestar de la tro$\mathrm{pa}$, los diputados temieron alguna reacción contra el Congreso, puesto que los problemas por los que atravesaba la hacían susceptible de rebelarse. Igualmente, la población de la ciudad de México desconfiaba de los desórdenes de los militares. No tardaron en llegar al Congreso diversas quejas presentadas por particulares sobre los atropellos protagonizados por los sol-

${ }^{29}$ En la sesión del 21 de marzo de 1822, este diputado, conocido antiiturbidista, propuso que se honrara la memoria de los primeros héroes de la patria, como Morelos e Hidalgo, y se derogara el decreto del generalísimo en donde no se admitía los méritos de la primera revolución. Ibid., t. II, p. 95. dados en la ciudad. El robo y el pillaje por parte de algunos de ellos para subsistir convirtieron la inseguridad ciudadana en otro grave problema que resolver. Una de las primeras protestas recibidas fue presentada por don Juan Eugenio Daza, quien solicitó que se castigaran los delitos de la tropa, que eran "muy notables y escandalosos en esta capital", de acuerdo con la real orden del 31 de agosto de 1772, es decir, exigiendo su desafuero. ${ }^{30}$ Este mismo individuo no tardó más que unos días en volver a enviar otra representación solicitando la supresión del fuero militar. La existencia de dicho privilegio provocó que algunos militares se valieran del mismo con el fin de cometer diversas tropelías y realizar otros abusos contra la población. La ausencia de un cuerpo organizado y disciplinado, que impusiera orden en la ciudad, facilitó la práctica del robo por algunos soldados ante la imposibilidad de la población para defenderse. A finales de enero de 1822 fue la misma comisión de guerra quien en su dictamen propuso desaforar a los militares acusados de robo. ${ }^{31}$ Sin embargo, el Congreso no llegó a ninguna conclusión sobre el tema temiendo el descontento que hubiera ocasionado entre la oficialidad, la tropa y en el mismo Iturbide, al contrariar el contenido del Plan de Iguala. A pesar de ello, las protestas recibidas y los informes sobre la tropa nos facilitan una idea aproximada de cuál fue el ambiente de desesperación y crispación ante la ausencia de control del gobierno sobre los soldados.

La preocupación y el temor por los acontecimientos transcurridos se pusieron

${ }^{30} \mathrm{Ibid}$., t. I, sesión del 29 de diciembre de 1821 , p. 177.

${ }^{31}$ Ibid., sesión de 22 de enero de 1822. 
de manifiesto en muchos de los debates parlamentarios. A mediados de 1822 el cuerpo legislativo manifestó su sospecha de que el descontento de la tropa pudiera dar lugar a revueltas de tinte absolutista, puesto que le llegaron rumores sobre vítores de algunos militares a favor del gobierno autoritario o personal. ${ }^{32}$ Las sospechas del Congreso -mayoritariamente borbonista, como hemos indicado- no andaban ciertamente muy desencaminadas puesto que a mediados del mes de mayo de 1822 parte del ejército, con el apoyo del sector iturbidista, forzó al Congreso a coronar a Iturbide como emperador.

Los desórdenes de la tropa fueron en aumento y todavía en julio de 1822 , siendo Iturbide emperador, el conflicto no había sido resuelto de ningún modo. En la sesión del 29 de julio de 1822 el diputado Pascual Aranda mostró pasquines situados en las puertas de la catedral en los que se aludía al riesgo que corría la paz pública al no haberse auxiliado al ejército permanente y en donde se inculpaba al Congreso de esta falta. ${ }^{33}$ La discusión suscitada derivó a reconocer la inexistencia de una justicia que condenara a los culpables debido a la lentitud con la que se ejercía, pero lo cierto es que sin una institución que garantizase el orden difícilmente podía detenerse y juzgar a los culpables, y menos si éstos pertenecían al ejército.

Desde su proclamación, el emperador, al mismo tiempo que llamó a la calma,

${ }^{32}$ Para evitar esto el 3 de agosto de 1822 algunos diputados propusieron, como ya hemos mostrado, declarar traidor a todo aquel que promoviera el gobierno absoluto 0 atacara al gobierno vigente, es decir, el monárquico constitucional. Ibid., t. III, sesión del 3 de agosto de 1822.

${ }^{33}$ Ibid., sesión del 29 de julio de 1822, pp. 337340.

EJÉRCITO Y MILICIA CÍVICA trató de poner fin a los robos perpetrados por los soldados a través de diversos llamamientos a la tropa; pero apenas obtuvo respuesta y el descontento de la población no favoreció a nadie. En una de esas proclamas, el 22 de mayo de 1822, solicitó la exacta observancia de las leyes, demandando orden y disciplina: "Disciplina y orden son los caracteres del soldado y no hay ejército cuando entre los que lo componen se olvida la subordinación justa, la escrupulosa honradez, la generosidad de sentimientos [...], la austeridad de las costumbres, el respeto a las propiedades." 34 Nuevamente, el 3 de junio de 1822 volvió a dirigirse al ejército y al pueblo para explicar un acontecimiento acaecido y llamar la atención sobre la conducta de una parte del ejército que actuaba fuera de la ley. El acontecimiento hacía referencia a un regimiento de la capital que había proyectado el asalto a casas de comercio. Iturbide trató de hacer entender que comprendía el mal estado por el que atravesaba el ejército pero no justificaba el acto:

sin embargo de que la necesidad suele ser causa de que los hombres falten a cuanto deben a sus conciudadanos y aun a sí mismos y me consta de que en el mes pasado se dejó de satisfacer a los cuerpos más de una cuarta parce de los que para su preciso alimento se les suministra, no creí que soldados del imperio pudieran abandonarse hasta el extremo de iniquidad. ${ }^{35}$

Ninguna de estas proclamas tuvo el efecto deseado y los desórdenes siguieron estando presentes en la capital. El "partido del orden", agrupado en las filas imperia-

\footnotetext{
34 "Al ejército" en Cuevas, Libertador, 1947, p. 345.

${ }^{35}$ Ibid., p. 349.
} 
les, flaqueaba allí donde más énfasis ponía para reclamar su superioridad, dándose la impresión de descontrol en su principal instrumento, las fuerzas leales del ejército permanente, camino de convertirse en una desbandada pretoriana.

A pesar de los obstáculos, el Congreso nunca desistió de su idea de aplicar el decreto de milicias para solucionar el orden y la defensa de todo el país, pero el emperador frenó la aplicación de esta medida. ${ }^{36}$ Del mismo modo, el legislativo continuó vetando las propuestas del emperador a favor del pago y aumento del ejército. De hecho, y para evitar la intromisión del emperador en las decisiones del Congreso, se le suspendió el derecho a veto a pesar de que la Constitución de 1812 reconocía tal privilegio al rey. ${ }^{37}$ El emperador, que poseyó más poder como regente, protestó enérgicamente al Congreso acusándolo de no cumplir la ley vigente, si bien en alguna ocasión él mismo se había opuesto abiertamente a algún apartado de la misma. El problema quedó en el aire, pues antes de que pudieran llevarse a la práctica algunas de las providencias adoptadas, el Congreso fue disuelto por orden del emperador poco después de que se produjeran las detenciones de los diputados.

\section{LA MIIICIA CÍvICA}

En el mes de marzo de 1822 se propuso en el Congreso el establecimiento de la milicia en todo el imperio, como el medio económico más adecuado para mantener

\footnotetext{
${ }^{36}$ A mediados de junio protestaron por la falta de aplicación del reglamento de milicias en el imperio por parte del ejecutivo. Actas, 1980, t. IV.

${ }^{37}$ Colección, 1836, p. 234.
}

un cuerpo armado que defendiera la libertad, la integridad y la independencia del país. ${ }^{38} \mathrm{La}$ escasez de la Hacienda nacional impedía, en parte, sustentar un ejército permanente cuantioso y extensible a todo el imperio, según se afirmaba. Pero no era únicamente una cuestión económica. La desconfianza ante un ejército fiel en su mayoría a Iturbide y acantonado en la capital llevó al Congreso a intentar crear una fuerza armada de confianza. El Congreso vio en la milicia el cuerpo armado que defendería los intereses del nuevo Estado constitucional y pondría freno a los intentos de instalar un gobierno absoluto o disolver el Congreso, rumores todos ellos que llegaban a oídos de los diputados.

En las Cortes de Cádiz, donde algunos de los diputados novohispanos tuvieron una participación destacable, se dio forma a la milicia nacional pensada para la defensa del régimen liberal y como freno a las tendencias absolutistas de una parte de la oficialidad del ejército. ${ }^{39}$ Este reglamento de la milicia llegó a aplicarse en los territorios americanos $y$, aunque posteriormente fue abolida por el gobierno fernandino en 1814 , en 1820 volvió a aprobarse un reglamento que en México, entonces Nueva España, llegó a aplicarse en septiembre de ese mismo año. ${ }^{40}$

La milicia nacional recibió el nombre de milicia cívica en México y fue aprobada en sus dos vertientes: una milicia local facultada para la defensa del orden interno en las poblaciones y una milicia a escala

${ }^{38}$ Actas, 1980, p. 30, sesiones del 1 y 9 de marzo de 1822. Es el diputado Tejada quien propone esta alternativa al ejército permanente.

${ }^{39}$ Sobre la milicia nacional en España. Pérez, Milicia, 1978.

${ }^{40}$ Chust, "Milicia", 2002, pp. 361-364. 
provincial encargada de la defensa del país y de conservar la integridad nacional, tanto del peligro de invasión por potencias extranjeras como de las amenazas interiores que pudieran surgir o que ya estaban presentes, como la lucha contra los pueblos indios del norte.

Durante los meses de abril, junio y julio de 1822 se fueron aprobando los artículos del decreto sobre la milicia presentados por la comisión. En ese momento los enfrentamientos entre el Congreso e Iturbide fueron más evidentes y constantes los rumores sobre las intenciones insurrectas. Sin embargo, apenas surgieron divergencias en los debates parlamentarios aunque algunos fueron muy destacables. Así, la intervención del diputado Domingo Luaces, militar e iturbidista, propuso que la milicia cívica estuviera dirigida por oficiales veteranos, lo que en la práctica suponía una subordinación al ejército profesional. ${ }^{41}$ La reacción de los diputados opuestos a Iturbide no se hizo esperar: tanto Carlos Ma. de Bustamante como Arganda se opusieron, entendiendo que la milicia debía ser completamente independiente del ejército para cumplir con su cometido, que no era otro que el de defender el orden del Estado liberal establecido y, al mismo tiempo, ser transmisora a la sociedad de esos ideales. EI diputado Castellanos lo argumentó de este modo: "Dos son los objetos que se han propuesto los gobiernos libres en el establecimiento de las milicias cívicas: uno resistir con ellas a los enemigos exteriores, y el otro sostener la libertad contra el déspoca, que valiéndose de la tropa veterana intente atacarla." 42

${ }^{41}$ Actas, 1980 , t. II, sesión del 18 de abril de 1822, p. 52.

${ }^{42}$ Ibid., p. 53.
Y esto último era fundamental en el contexto que se estaba viviendo, teniendo en cuenta la indisciplina de la tropa y las intromisiones de Iturbide en la labor del Congreso. Para el diputado Castellanos, el sistema debía infundir la confianza necesaria en los ciudadanos y eso sólo podía conseguirse mediante la implantación de la milicia, pues no era suficiente con afirmar que el ejército no tenía malas intenciones o que defendería el sistema, había que garantizarlo.

De este modo, quedó de manifiesto en el debate cuál iba a ser la funcionalidad de la milicia: no sólo la defensa de la nación frente a los supuestos enemigos externos e internos del país, sino que iba a convertirse en el sustento del gobierno constitucional establecido o, para ser exactos, en el sustento del cuerpo legislativo, esto es, representativo de la nación, y en el contexto del momento, de los grupos sociales más activos que reclaman la representación. Sobre la milicia recaería el cometido de proteger al Estado liberal de las intenciones autoritarias que pudieran florecer. Para el Congreso, el Trigarante era ahora el brazo armado de Iturbide y, frente a él, la milicia representaría las fuerzas del orden político y social constitucional. Ciertamente las diferencias existentes entre el Congreso e Iturbide se vieron exacerbadas, impidiendo la posibilidad de un acuerdo ante la desconfianza mutua. Fueron estas diferencias las que imposibilitaron el correcto funcionamiento y gobierno del país y desprestigiaron a ambos cuerpos de cara a la opinión pública, mientras los gobiernos locales de las provincias vieron que sus intereses eran relegados. Finalmente, la proposición del general Luaces no salió adelante ante el desacuerdo suscitado, aunque sí se permi- 


\section{SECUENCIA}

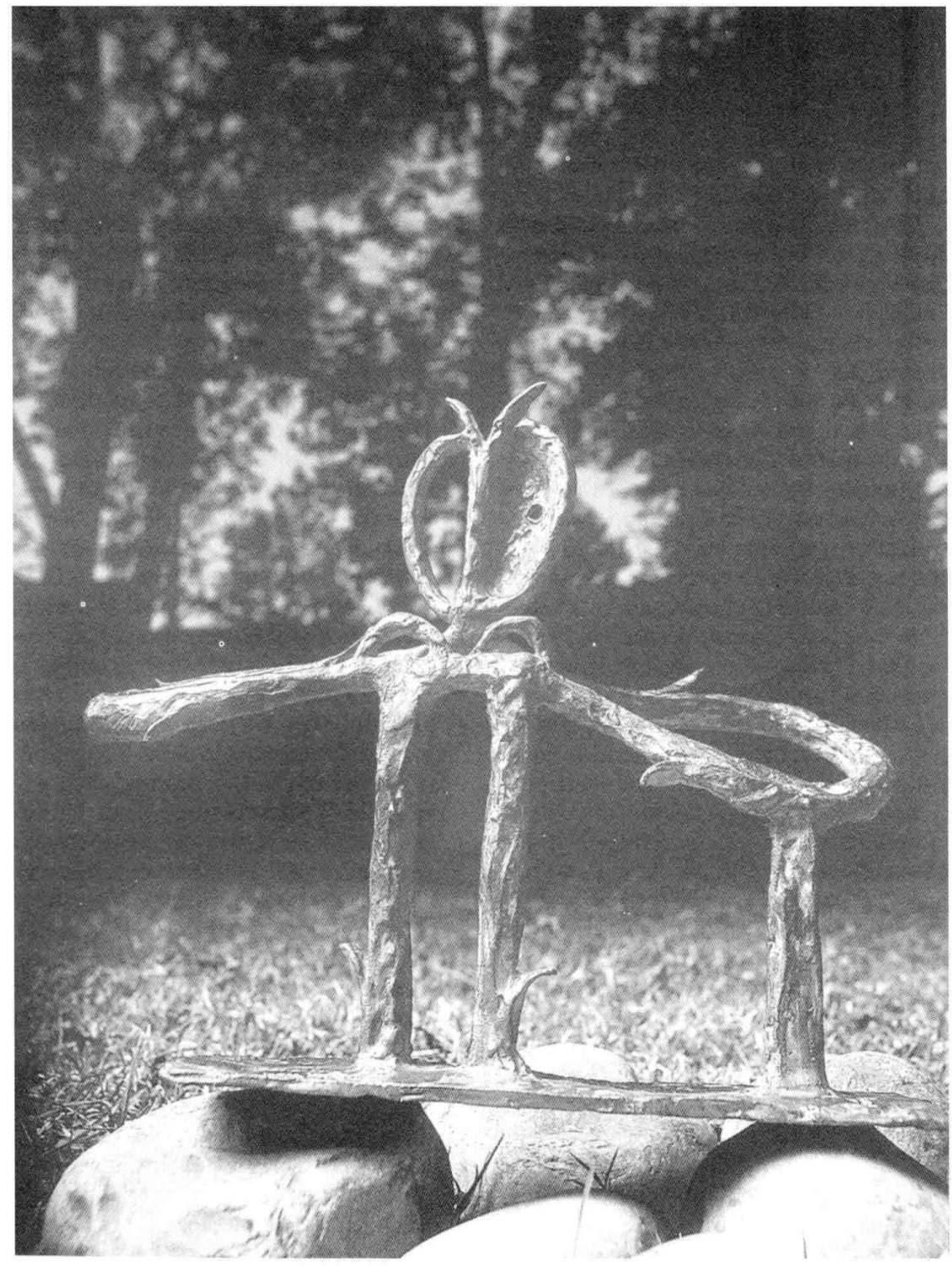


tió que los oficiales retirados, y por voluntad propia, pudieran presentarse y ser elegidos para desempeñar en la milicia el cargo o las funciones que correspondieran a su grado o a otro superior, nunca inferior.

En el primer capítulo del decreto, aprobado en la sesión del 18 de abril de 1822 , se concretó quién debía formar parte de la milicia, así como la fuerza y composición de la misma de acuerdo con el número de integrantes. Integrarían la milicia todos los ciudadanos comprendidos entre los 18 y 50 años con la excepción de clérigos, marinos, simples jornaleros, los que tuvieran impedimento físico alguno que no les permitiera el manejo adecuado de las armas y los funcionarios públicos, civiles y militares. ${ }^{43}$ Salvando a los eclesiásticos, el resto de los exentos podían entrar a formar parte de la milicia por voluntad propia. ${ }^{44}$ Resumiendo, la milicia estaría compuesta por el grueso de la población civil y propietaria, es decir, aquella población con mayor interés en la conservación y preservación de un gobierno constitucional, pues como dijo el diputado Castillo "sólo en los tiempos del gobierno absoluto estaba la milicia reducida a la plebe, pues en las naciones célebres y siglos felices, los soldados eran de las clases selectas". 45

Para justificar las posibilidades reales de los milicianos en una situación de guerra frente al soldado instruido los diputa-

${ }^{43}$ Por "simples jornaleros" se entendía, de acuerdo con las actas, a todos aquellos operarios $u$ oficiales que vivían de su trabajo del día. Es decir, aquellos que "no ganan jornal el día que no trabajan". Ibid., p. 54.

${ }^{44}$ Dublán y Lozano, Legislación, 1876, p. 619.

45 Actas, 1980, t. II, sesión del 18 de abril de 1822, p. 54. dos recurrieron en más de una ocasión al ejemplo español y su guerra contra el francés para demostrar que la población civil podía y debía luchar para preservar sus bienes, pues era la más interesada en la conservación de los mismos. ${ }^{46}$

El segundo capítulo del decreto hizo referencia a las obligaciones de la milicia. Bajo su responsabilidad permanecería la seguridad pública en el interior del término de los respectivos pueblos en los que se hubiera creado y, en general, la defensa de cualquier agresión, ya fuera interior o exterior. Realizaría, de igual forma, aquellas tareas propias de la tropa en defecto de ésta, como la escolta de presos y caudales hasta el pueblo inmediato. ${ }^{47}$ Estas responsabilidades corresponderían técnicamente a la llamada milicia local. En el ámbito provincial tendría la obligación de defender la nación ante cualquier ataque cuya intención fuera la destrucción del estado constitucional vigente.

La milicia cívica dependería directamente de la autoridad superior política local, consolidando así su carácter civil y su independencia con respecto a cualquier cargo militar. Se sugirió, en los debates del Congreso, que no hiciera honores a nadie excepto a la majestad divina y que esta práctica se extendiera al ejército permanente con el fin de evitar una posible rivalidad entre ambos cuerpos, cuestionando el origen de esta práctica que se encontraba en el "orgullo de los tiranos" conforme a la opinión de los diputados. ${ }^{48} \mathrm{El}$

\section{${ }^{46}$ Ibid.}

${ }^{47}$ Dublán y Lozano, Legislación, 1876, p. 620.

${ }^{48}$ Actas, 1980 , c. II, sesión del 10 de mayo de 1822, p.197. La propuesta es de Francisco Tarrazo, mientras que la idea de extenderla a la tropa fue de Joaquín Herrera. 
objetivo de la propuesta no era otro que la desvinculación del ejército del juramento que lo hacía dependiente del poder ejecurivo, pasando a depender del legislativo $o$, al menos, obligarlo a jurar lealtad a los derechos básicos constitucionales $\mathrm{y}$, por ende, al Congreso. Sin embargo, la proposición no salió adelante y el mismo Carlos Ma. de Bustamante concluyó que, a pesar de lo "detestable" de la práctica, era necesario que la milicia profesional conservara el juramento a algún cuerpo "hasta que el vulgo se ilustre y persuada que los verdaderos honores y la mejor guardia de un soberano, consiste en el ejercicio de sus virtudes". ${ }^{49} \mathrm{La}$ finalidad de las palabras del diputado no fue otra que la de evitar recelos del ejército contra el Congreso, pues en ese momento estaba demasiado vinculado a la figura de Agustín de Iturbide y bajo su mando, como para desprenderlo del juramento. Al no adoptarse esța medida, la milicia quedó vinculada al poder legislativo, no debiendo dar guardia de honor a ninguna persona ni facción. El mismo juramento que debían cumplir los comandantes de la milicia dejaba ver su futura subordinación:

¿Juráis a Dios [...] obedecer y hacer obedecer lo sancionado por el Congreso nacional, guardándole la más acendrada fidelidad, como depositario de la soberanía, obedecer exactamente a las autoridades locales civiles, y guardar la debida consideración a los demás ciudadanos? ${ }^{\text {?0 }}$

${ }^{49}$ Contestación de Carlos M. Bustamante a la exposición del diputado Francisco Tarrazo, en ibid. p. 197.

so Dublán y Lozano, Legislación, 1876, p. 622.
En oposición al ejército permanente, los oficiales de la milicia debían ser elegidos por pluralidad de votos. Aquellos que quisieran aspirar a la ocupación de los cargos tenían que cumplir un mínimo de requisitos: haber nacido en América o haber residido un mínimo de siete años en el pueblo correspondiente y ser adicto a la independencia. A partir de ahí, los méritos obtenidos posibilitaría su elección y ascenso en el cuerpo. Así, la organización de la milicia se mostró más acorde con el nuevo sistema de gobierno de igualdad entre ciudadanos ante la ley frente a las ordenanzas de un ejército donde la nobleza de sangre y el linaje, es decir, donde los privilegios del anterior régimen seguían siendo los requisitos fundamentales para formar parte de la oficialidad a pesar de que los ascensos en la guerra habían quebrado esa situación. Indudablemente se propuso la redacción de una nueva ordenanza para el ejército que eliminara los rasgos propios del antiguo régimen, pero los diputados no dispusieron de tiempo suficiente para llevar a la práctica esa tarea, pues decidieron aprobar primero el reglamento de la milicia y a continuación el Congreso Constituyente fue disuelto por el emperador.

El resto del articulado del reglamento comprendía todo lo relacionado con el modo de recibir la instrucción y a quién correspondía impartirla, así como las penas que se aplicarían en caso de necesidad y cómo debía procederse en la reclamación de las mismas. También se incluyó el uniforme, la bandera y el estandarte que distinguirían a los integrantes de la milicia. Ningún miliciano debía ser forzado a vestir el uniforme, aunque sí debía portar la escarapela, la fornitura y las armas correspondientes. Para fomento de la industria 
textil se aprobó que los uniformes fueran realizados con paños nacionales. La población civil que formara parte de estas compañías de milicias no disfrutaría de fuero alguno frente al privilegio que los militares habían conservado, defendiendo así la idea de la igualdad de los ciudadanos ante la ley.

Los fondos de la milicia debían obtenerse de la recaudación de las penas pecuniarias impuestas a los milicianos, así como por lo obtenido a través de los arbitrios que el ayuntamiento creara para tal objetivo, tras previa aprobación del gobierno. Todo lo recaudado tenía que ser depositado en los ayuntamientos de cada pueblo, en un arca con una cerradura de tres llaves. Una de las llaves permanecería en posesión del alcalde primero y las otras dos en manos del tesorero del ayuntamiento de cada pueblo y del oficial de mayor graduación de la milicia como medida preventiva para evitar estafas o robos. Las milicias que se habían mantenido en algunas zonas debían readaptarse al nuevo reglamento y proceder a las elecciones correspondientes. De hecho, esto es lo que aconteció en algunas partes del territorio en las que se conservaron los batallones de la milicia nacional establecidas por el gobierno constitucional del Trienio. El reglamento era muy similar, así que la readaptación fue simple y rápida. ${ }^{51}$

$\mathrm{La}$ aplicación del reglamento de la milicia en todo el territorio nacional debía convertir a ésta en el cuerpo armado asociado al sistema constitucional cuyos principios e intereses eran compartidos especialmente por los individuos que formaban parte de las milicias, pertenecientes a una clase media que crecía a la sombra

s1 Chust, "Milicia", 2002, pp. 361-379. del nuevo sistema económico. Todo lo contrario de lo representado por el Ejército Trigarante que si bien, como ya hemos señalado, se caracterizó por su heterogeneidad, se regía todavía por las antiguas ordenanzas, lo que en parte también provocó conflictos internos.

El enfrentamiento más directo entre el ejecutivo y el legislativo por el desarrollo de una milicia cívica fuerte frente a un ejército carente de fondos, que el Congreso pretendía debilitar, tuvo lugar en la discusión que se planteó sobre la defensa del país. Después de la propuesta presentada por el secretario del Despacho de Guerra, el Congreso decidió entrar en la cuestión sobre la reorganización de las fuerzas armadas a escala nacional. Durante el debate, que se extendió a lo largo de varios días, se expusieron cuestiones significativas para entender el ambiente de inestabilidad del momento y la inseguridad que los diputados sentían respecto a la continuidad del régimen constitucional, así como la desconfianza de muchos respecto a la figura de Agustín de Iturbide y viceversa.

\section{MILICIA CÍVICA O EJÉRCITO PERMANENTE EN LA DEFENSA DE LA NACIÓN}

El 22 de marzo de 1822 el secrecario del Despacho de Guerra informó al Congreso sobre el número y la clase de tropas que la Regencia consideraba necesarias para llevar a cabo la defensa del país. En el informe se argumentó la existencia de numerosos peligros que amenazaban la independencia del país, como posibles invasiones promovidas por el gobierno inglés o español, y la inestabilidad de algunas zonas internas, como las provincias del norte por la situación permanente de guerra contra las tri- 
bus indias, o las mismas Californias, que aún no habían presentado el juramento al nuevo gobierno. La pretensión era que unos 35900 hombres formaran el ejército permanente y que, al mismo tiempo, se activara la milicia, tanto local como provincial, pero con un número menor de componentes que aquél. El Congreso trasladó el informe a la comisión de guerra, que fue la encargada de instruirse y decidir sobre la opción más adecuada. Para mejor conocimiento del asunto y de.la situaciôn del país, así como de sus necesidades reales, el Congreso resolvió que se agregase a la comisión correspondiente un diputado por cada provincia. ${ }^{52}$ Unos días más tarde la comisión presentó el dictamen con sus deliberaciones donde manifestó su disconformidad con la propuesta presentada por la Regencia y se resolvió que la defensa del país recayera, principalmente, sobre la milicia cívica cuyo número de componentes sería mayor que el grueso del ejército permanente, es decir, 35000 hombres constituirían la milicia cívica frente a unos

52 Los diputados agregados a la comisión de guerra fueron: Agustín Paz, por México; Osores, por Querétaro; Pablo Anaya, por Guadalajara; José Ignacio Esteva, por Veracruz; Castellanos, por Mérida; Javier Bustamante, por Oaxaca; José María Septién, por Guanajuato; Ignacio Izazaga, por Valladolid; Conde de Peñasco, por San Luis Potosí; Francisco García, por Zacatecas; Guridi y Alcocer, por Tlaxcala; Juan Bautista de Arizpe, por Monterrey; Manuel Gutiérrez, por Nuevo Santander; Ramos de Arizpe, por Coahuila; Guerra, por Texas; Francisco Velasco, por Durango; Juan Miguel Riesgo, por Sonora; Francisco Rivas, por Nuevo México; Martínez de Vea, por Alta California; Ortiz de la Torre, por Baja California; Manuel de Terán, por Chiapa; Manuel Flores, por Quesaltenango, y Larrabe por Guatemala. Actas, 1980, t. Il, sesión del 15 de abril de 1822, pp. 29-30.

${ }^{53}$ Ibid., sesión del 29 de abril de 1822, p. 119.
20000 soldados profesionales. ${ }^{53} \mathrm{La}$ resolución de la comisión supuso en realidad un duro golpe al intento, por parte de Iturbide, de contentar y favorecer al ejército, pero el comportamiento inestable y sospechoso de éste unido a la desconfianza que algunos diputados mostraban hacia dicha alianza influyó en la decisión de los diputados que integraron la comisión. En aquellas fechas se habían difundido los rumores sobre el propósito de coronar al regente.

El primer debate en torno a esta cuestión transcurrió el 13 de mayo de 1822 con la presencia de los secretarios de los despachos de Hacienda, Guerra y Relaciones Exteriores; la discusión se dilató hasta el día 18. Hacía escasamente una semana que había comenzado la aprobación del reglamento de la milicia cívica, muy similar en todos sus artículos, como ya hemos reseñado, al reglamento que sobre la milicia nacional aprobaron las Cortes de Cádiz. ${ }^{54}$

Desde el comienzo de los debates se perfilaron dos posturas definidas con arreglo a las dos propuestas existentes, la presentada por la Regencia y la expuesta por la comisión. La argumentación de la Regencia sobre la presencia de los peligros enumerados se convirtió en una parte importante del discurso desplegado por los diputados, puesto que de su posibilidad real dependía la necesidad de formar un ejército permanente dotado de mayor o menor contingente. La invasión por parte de una potencia marítima como Inglaterra se percibió como una posibilidad debido a la proximidad de algunas tropas inglesas

${ }^{54}$ Chust, "Milicia", 2002, pp. 361-379. Sobre los temas americanos en las Cortes de Cádiz véase del mismo autor, Cuestion, 1999. 
asentadas, de acuerdo con los diputados, en Jamaica, y por el interés que este país mostraba por el dominio del mercado americano. ${ }^{55}$ Pero el mayor peligro, siempre de acuerdo con los diputados iturbidistas, lo representó el riesgo de sufrir una invasión por parte del ejército español. La cercanía de Cuba, por donde se suponía que las tropas podían preparar un ataque, y el hecho de que todavía por estas fechas la fortaleza de San Juan de Ulúa estuviera bajo dominio español hizo temer lo peor. A esto había que añadir el inconveniente del gobierno constitucional español que se negaba a reconocer la independencia de los territorios americanos.

Es indudable el recelo y temor que algunos representantes mexicanos mostraron en sus discursos teniendo presente lo anteriormente expuesto, $y$ dado que por esas fechas ninguna potencia europea, y tampoco Estados Unidos, había reconocido la independencia del país. ${ }^{56}$ Las inquietantes noticias que llegaban a oídos de los diputados mexicanos no hacían más que confirmar esta idea. Para Carlos Ma. de Bustamante las palabras pronunciadas por el conde de Toreno en las Cortes españolas eran más que significativas de la postura de esta nación respecto a México: "España desplegará toda su energía para desarrollar su fuerza moral y su fuerza física sobre nosotros (los mexicanos)". ${ }^{57}$ Busta-

55 Actas, 1980, t. II, sesión del 13 de mayo de 1822, pp. 209-241.

${ }^{56}$ Ibid., sesión del 15 de mayo de 1822. En esta sesión el diputado Hipólito Odoardo protestó al gobierno porque todavía en estas fechas no había enviado comisionados al resto de los países para solucionar los problemas de las relaciones exteriores. 217.

${ }^{57}$ Ibid., sesión del 13 de mayo de 1822, pp. 211- mante, aunque conocía el estado de pobreza por el que atravesaba la antigua metrópoli, desconfió de sus intenciones al conocer, según sus palabras, que en Filadelfia se habían impreso folletos en los que el ministro Luis de Onís exhortaba a España para que vendiera en pequeñas porciones parte de América al resto de las potencias, lo que desembocaría inevitablemente en una guerra contra España o bien contra las supuestas potencias compradoras si México quería preservar su independencia. Para el diputado José Ma. Bocanegra el comportamiento de España respecto a la no aceptación de la independencia era del todo incoherente con las ideas liberales surgidas en el momento de la guerra contra el francés, en referencia a las Cortes de Cádiz y su Constitución, y desconfiaba de los diputados españoles, que en su opinión "son más que liberales en España pero serviles servilísimos para América" ${ }^{58}$

No menos importante fueron los peligros internos enumerados que ponían en riesgo la integridad nacional y el gobierno vigente. El iturbidista Pedro Lanuza destacó la inseguridad que se vivía en las provincias fronterizas del norte debido a la falta de control sobre las tribus indias que aún no habían sido civilizadas, mientras que las Californias todavía no habían jurado su independencia y adhesión al nuevo régimen, recalcando además la situación del Castillo de San Juan de Ulúa bajo el mando del coronel Dávila. ${ }^{59} \mathrm{Al}$ mismo tiempo, el diputado Santiago Alcocer destacó que en el país permanecían todavía numerosos enemigos del gobierno y de la

${ }^{58}$ Ibid., exposición del diputado Bocanegra, p. 230.

59 Ibid., pp. 218-219. Véase Ortiz, "Defensa", 2002, pp. 155-196. 
independencia que esperaban una oportunidad para entrar en guerra, lo que viene a traducirse en la necesidad de un ejército fuerte y numeroso que pudiera contrarrestar estos peligros. ${ }^{60} \mathrm{Si}$ reconocemos todos estos inminentes riesgos como reales, la situación del país era potencialmente comprometida, pero contradecía lo expuesto por Iturbide en los primeros discursos que hizo a la nación tras el triunfo de la independencia. ${ }^{61}$ Esta incoherencia resultó sospechosa para algunos diputados que intuían en la actitud del gobierno, y particularmente en la del regente Iturbide, un intento por reforzar su poder a través del fortalecimiento del ejército. Uno de esos diputados fue Hipólito Odoardo, de quien haremos referencia más adelante.

La aceptación de la amenaza no inclinó a los diputados hacia la misma conclusión respecto de en quién debía recaer la defensa de la nación. Para Lanuza era esencial la formación de un ejército permanente poderoso que defendiera al país de estos potenciales enemigos. Era partidario de un gobierno fuerte que se hiciera respetar tanto a escala internacional como dentro del país, afirmación que nos lleva a deducir la defensa del centralismo frente a las voces de disconformidad que empezaban a surgir de las provincias por el control de su gobierno local. Para conseguir esto y de acuerdo con su argumentación, lo más conveniente era la formación de una fuerza coercitiva que sostuviera y aplicara sus decisiones entendiendo que la milicia cívica sólo podía considerarse como una ayuda extra en caso de necesidad:

${ }^{60}$ Actas, 1980, t. II, sesión del 15 de mayo de 1822, pp. 259-268. 1977.
Por otra parte, no perdamos de vista que las autoridades no son respetadas cuando no tienen fuerza que las sostenga: no las tengamos para obrar, pero las necesitamos para imponer. Todas las revoluciones, dice un sabio político veneciano, tuvieron su origen en el desprecio con que se miró a los que mandaban. ${ }^{62}$

De este modo, Lanuza se inclinó hacia el fortalecimiento del poder ejecutivo dentro de la separación de poderes, contraviniendo en realidad las actuaciones generales del Congreso que estuvieron dirigidas en la mayoría de los casos a limitar el poder del ejecutivo frente a un legislativo que debía ser dominante, como correspondía al representante de la soberanía de la nación. Por otro lado, Lanuza reconoció que la indisciplina del ejército podía resultar un arma peligrosa pero, asimismo, afirmó que la solución venía determinada por hacer cumplir las ordenanzas con energía. En su opinión, el ejército era un instrumento que había que saber controlar y a través del cual se imponían las decisiones y las medidas aprobadas. Del mismo sentir respecto a la importancia del ejército fueron los diputados José Ma. Bocanegra y Antonio Valdés. Ambos confiaban únicamente en la buena preparación del ejército profesional para hacer frente a la contienda y, de este modo, coincidían en que su establecimiento sería el único modo en que el país lograra ser respetado por el resto de las naciones extranjeras. Lanuza destacó nuevamente la ausencia de fondos como un problema para poder sufragar el gasto del ejército, pues la comisión de guerra había hecho uso de este argumento para favorecer la formación de la milicia

${ }^{62}$ Actas, 1980, t. II, sesión del 13 de mayo de 1.822, p. 224. 
cívica, pero sin dar una alternativa al problema suscitado, optó por culpar a la Junta Suprema de la supresión de las contribuciones consideradas injustas, sin haberlas sustituido por otras propias de un sistema liberal.

Aunque en las actas no se incluyen los discursos expuestos por los secretarios de Despacho, las respuestas de los diputados dan idea de los numerosos peligros que presentaron como posibles. Además, en una carta que, con motivo de esta discusión, Iturbide dirigió al resto de los miembros de la Regencia, y que posteriormente debía ser enviada al Congreso para su información, afirmaba que

por Wallis nos amenazan los ingleses; por Tejas se interesan nuestros vecinos; por varios puntos de la frontera Oriente las naciones bárbaras, por Guatemala la anarquía, por las Californias los rusos, por Veracruz los españoles, por las provincias la guerra civil, y por todas partes todas las naciones de Europa, los embajadores se retiran del país que nos reconoce, en Cádiz se apresan buques de la armada, en Madrid nos llaman traidores, en Londres, París y Lisboa hay emisarios de nuestros antiguos dominadores. ${ }^{63}$

Además de esta enumeración, en la que trató de convencer al resto de la Regencia de la necesidad de la fuerza armada, atacó al Congreso indirectamente haciendo referencia a la situación por la que atravesaba el país sin una Constitución, sin ejército, sin Hacienda debido a los problemas económicos y sin separación de poderes, según destacó, solicitando al final del es-

${ }^{63}$ Carta de Iturbide dirigida a la Regencia fechada en México el 15 de mayo de 1822 en Cuevas, $L i$ bertador, 1947, pp. 341-342. crito que el ejército se integrara de 35000 hombres. Lo cierto es que los problemas económicos eran evidentes y acuciantes, pero la aprobación de un gran contingente no iba a ayudar a la Hacienda nacional y todavía, a estas alturas, el Congreso no había iniciado la redacción de una constitución propia, pues, aunque relevante, parecía de momento más preocupado en su posición y el gobierno vigente para su perdurabilidad en el tiempo.

En contraste con esta exposición, Carlos Ma. de Bustamante apoyó el dictamen de la comisión considerándolo el más apropiado debido a las circunstancias por las que atravesaba el país, pues la inexistencia de recursos hacía inevitable que se prefiriera la implantación de la milicia como método más económico. Solicitó la reducción de la tropa a 20000 hombres, pues confiaba en lo abrupto de las costas mexicanas como la mejor defensa, lo que impediría los desembarcos de las tropas extranjeras, así como en lo complicado de la geografía interior del país. Pero más que la confianza en la orografía fue la desconfianza en el Trigarante lo que le llevó a sostener la propuesta de la comisión. A pesar de todo, la falta de recursos era un problema real que debía ser solucionado cuanto antes, por ello presentó su particular propuesta:

La baca América [sic] se ha ordeñado sin piedad: hánsele secado las ubres, y no dará ya más leche si no se le suministra alfalfa en abundancia: el pasto jugoso que le hará producir, será facilitar el comercio, minorando todo lo posible los derechos, amparando la industria y protegiendo la propiedad. ${ }^{64}$

${ }^{64}$ Actas, 1980, t. II, sesión del 13 de mayo de 1822, pp. 211-217. 
De acuerdo con su argumentación, los nuevos valores que se pretendían potenciar dentro de la sociedad debían ser protegidos por un cuerpo que dependiera directamente del legislativo como representante de la soberanía. Declarado republicano y antiiturbidista, Bustamante puso en duda en más de una ocasión las intenciones de Iturbide, de quien desconfiaba y consideraba representante de los valores más tradicionales. Es por ello que su inclinación por la milicia cívica fue no sólo una cuestión económica, sino que desde su punto de vista implicaba la vigencia, o no, del sistema constitucional establecido. Bustamante dirigió un escrito a Iturbide en el cual debió pedirle o aconsejarle que no se opusiera a los decretos y decisiones aprobados en el Congreso. Disponemos de la respuesta que Iturbide dio al diputado, fechada unos meses después de que se diera esta discusión y que es muy significativa sobre la relación entre ambos cuerpos:

pero permítame usted [Carlos Ma. de Bustamantel le diga que mi delicadeza se resiente de que se me considere capaz de abrigar de disconformidad con el soberano; respeto profundamente la voluntad general, y no haré ningún sacrificio en someterme a ella, antes por el contrario nada más deseo que ver las leyes que dicte para obedecerlas y cumplirlas gustosísimo.

¿Por qué me hacen ss el agravio de considerarme tan estúpido que no conozca las bondades de la unión? [...] persuádase usted de que no soy $\tan$ inconsecuente que quiera destruir mi hechura; de que soy más adicto al Congreso que los que me creen su enemigo; que lo sostendré a la par de las garantías que dan nombre al ejército que mando. Que soy yo un apreciador verdadero de estas corporaciones milagrosas de la política y la sa- biduría. Si pesamos en la balanza de la justicia con imparcialidad y sin pretensiones mi razón y la de ellos, que, sin saber el motivo se declararon. Aborrecedores de mi persona, me parece que la decisión será favorable. Amo al Congreso, veo en él el baluarte de la libertad, la esperanza de la patria, de esta patria que es mi ídolo. Pero algunos de los que lo componen, asestan contra mí sus tiros, juro que no soy enemigo de ellos, que les he dado pruebas de estimación, y les serviré cuando pueda como amigo, si mi representación les ofende, todo lo dejaré al fin. Sólo me sirve de paso, si esto puede tranquilizarlos y uniformar sentimientos. ${ }^{65}$

Se presentaron en el debate otros discursos mucho más contundentes y dirigidos a frenar la formación de una fuerza coercitiva de la que pudiera valerse cualquier persona para implantar un régimen de corte autoritario, o que pudiera poner freno al poder y las decisiones del legislativo. Odoardo, mucho más explícito en sus disertaciones, expresó el temor que producía en algunos diputados que la fuerza armada dependiera directamente del ejecutivo. En relación con los peligros expuestos, no creyó posible que se produjeran las invasiones que tan exageradamente la Regencia había referido en su informe para justificar su proposición. ${ }^{66}$

Contraviniendo la opinión del regente y de acuerdo con Hipólito Odoardo, las únicas potencias que tenían capacidad para llevar a cabo una conquista eran las marítimas y el interés de éstas; haciendo especial referencia a Inglaterra, se inclinaba

65 "Al señor don Carlos María de Bustamante" en Cuevas, Libertador, 1947, pp. 354-355.

${ }^{66}$ Discurso de Hipólito Odoardo en Actas, 1980 , t. II, sesión del 13 de mayo de 1822, pp. 234-241. 
más por lo comercial. En su opinión, un mercado de 16000000 de personas podía resultar útil y beneficioso para cualquier nación. En cuanto a una invasión de países como España y Rusia no creía que fuese económicamente viable, razón por la cual descartaba dicho argumento, al mismo tiempo confiaba en que Estados Unidos respetara la frontera limítrofe con México según el contenido del Tratado de Washington, en el cual quedaron delimitadas las fronteras entre ambos países. Tras esta argumentación, y una exposición sobre la maltrecha situación económica por la que atravesaba la nación, descartó sostener un ejército permanente que obligaría a tener que aprobar unas contribuciones insostenibles para la población. La milicia cívica resultó para él la alternativa más adecuada y, de acuerdo con sus palabras, la más compatible con el periodo por el que atravesaba el país. Es decir, la milicia era el cuerpo armado más adecuado para defender los principios liberales por los que se regía ahora el gobierno.

La exposición que el ministro de Guerra repitió en esta misma sesión, radicalizó aún más el discurso de Odoardo. Si bien en las actas no se incluye la disertación del ministro, la respuesta de Odoardo es más que significativa para intuir su contenido. El ministro, en representación de la Regencia y fiel a su propuesta inicial, volvió a insistir en los peligros que acechaban al país reiterándose en su propuesta sobre la composición del ejército. De acuerdo con su informe, la milicia todavía no se había establecido y tal operación necesitaba de tiempo y recursos, cosas de las que carecía el país. Hipólito Odoardo protestó enérgicamente por el comportamiento del gobierno por hacer uso de un infundado temor a las invasiones, exponiendo, al mismo tiempo, la falta de interés de la Regencia por el cuidado de las relaciones exteriores, puesto que todavía no había enviado ningún comisionado al extranjero para solicitar el reconocimiento de la independencia. Recelando del gobierno, el diputado se dirigió al Congreso requiriendo que el ejército permanente fuera menos dependiente del ejecutivo y se sometiera al legislativo: "La milicia permanente, por ahora unida a la nación [...] con el tiempo podría degenerar de sus patrióticos y loables sentimientos, y ser un instrumento en manos del gobierno para destruir las libertades de los pueblos." ${ }^{" 67}$ Los enfrentamientos cruzados habían llegado en este punto a su culminación con las acusaciones directas. Es obvio que se trata de conjurar el peligro del cesarismo.

En la misma línea, el diputado Francisco Tarrazo insistió y resaltó la peligrosidad de un ejército numeroso si no era estrictamente necesario y, a su juicio, no se había demostrado que así fuera puesto que éste había sido en muchas ocasiones "el instrumento de que se había valido un usurpador para subyugar un país libre". 68

A medida que avanzaron los debates la cuestión económica pasó a un plano secundario frente al temor de que el ejército fuera empleado para poner fin al sistema de gobierno vigente. El 17 de mayo el Congreso aprobó por votación que el ejército permanente se dotara con 20000 hombres y que la milicia local y provincial fueran reactivadas y rearmadas con una adjudicación de 30000 hombres. El Congreso se había vuelto a oponer abiertamente a las propuestas de Agustín de Iturbide.

${ }^{67}$ Ibid., pp. 263-264.

${ }^{68}$ Ibid., sesión del 15 de mayo de 1822, p. 257. 
Estas deliberaciones en el seno del Congreso no gustaron al ejército acantonado en la ciudad, ni tampoco debieron de ser del agrado de Iturbide. Los debates sobre el resto del articulado relativo a las fuerzas armadas quedaron paralizados en ese momento a causa del levantamiento militar. El 19 de mayo el presidente del Congreso citó a los diputados para que asistieran a una reunión extraordinaria con el fin de leer un oficio del ministro de Guerra en el que informaba sobre el manifiesto firmado por algunos generales, jefes y oficiales del ejército del imperio, existentes en la capital, que habían decidido proclamar a Agustín de Iturbide emperador de la América mexicana y solicitaban que el Congreso deliberase sobre tal decisión. ${ }^{69}$

Tras la lectura de dicho manifiesto se procedió a la lectura de otro, esta vez de

69 Ibid., sesión extraordinaria del 19 de mayo de 1822. Los firmantes del manifiesto eran: Pedro Celestino Negrete, Manuel Sotarriva, Anastasio Bustamante, Luis Quintanar, Manuel María de Torres, Diego García Conde, Marqués de Vivanco, José A. de Echávarri, Joaquín Parres, José Armijo, Rafael Ramiro, Ignacio del Corral, Conde de S. Pedro Álamo, José Mendivil, José F. Guerra de Manzanares, Pedro Otero, Francisco de las Piedras, Francisco M. Hidalgo, José A. Matiauda, Diego Rubín de Celis, José María González Arebalo, Mariano Paredes Arrillaga, Manuel de la Llara, Ramón Carrillo, José Mariano Guerra, José María Quintero, Tomás Illanez, Carlos de Urrutia, Antonio Ruiz de Esparza, Santiago de Menocal, Francisco de Paula Tamariz, Miguel Soto, Miguel Cabalero, Marqués de Salvatierra, Bonifacio de Hosta, Vicente Domínguez, José Camino, José Guadalupe de Palafox, Marques de Casa de Cadena, Bernardo Amat, Marqués de Uluapa, Ramón de Rey, Juan J. Rubio, José María de Gondra, Vicente del Rivero, Narciso Sort de Sans, José María Mendiola, Félix María Survarán, José María Quintana, Mateo Qüilty Valois, Mariano Chico, Ignacio de la Blanca, Juan de
Iturbide, en el que se dirigía al pueblo de la ciudad de México comunicando la decisión que había tomado pero que esperaba ver ratificada por la nación, es decir, que debía dejarse deliberar al Congreso sobre el tema. La primera duda suscitada por los diputados reunidos en el Congreso fue la existencia de quórum suficiente para que pudiera votarse en la reunión; finalmente se optó por admitirlo. Es importante esta cuestión porque en el futuro, una vez que Iturbide hubiera renunciado como emperador y el Congreso hubiera sido restablecido, uno de los alegatos argumentados para afirmar la ilegalidad de la coronación hubiera sido la falta de quórum en el Congreso el 19 de mayo, razonándose que los diputados fueron presionados y forzados a ratificar la investidura. Sea cierto o no, resulta evidente que los diputados carecieron de libertad para reprobar tal acto a juzgar por el contenido de las actas. Al parecer, la población de la ciudad rodeó enfurecida el edificio del Congreso increpando a los diputados para que aceptaran a Agustín de Iturbide como emperador. Los representantes debatieron celebrar la sesión a puerta cerrada pero la multitud agolpada no lo permitió. Para contener y controlar al gentío, una comisión de cuatro diputados tuvo que solicitar a la propia Regencia que se responsabilizara de la seguridad de los representantes de la nación para que pudieran deliberabar con independencia. La comisión no obtuvo una respuesta tranquilizadora hasta que el propio Iturbide fue invitado a asistir a la sesión extraordinaria. La falta de libertad

Aragó, Francisco Olmedo, Pablo Unda, José María Fernández, José R. Malo, Juan de la Peña y del Río, Manuel de Lebrija, Manuel F. Casanova, Alvino Pérez, José Bernal, José Falcó y Escandón y José Portillo. 
para debatir y el interés de Iturbide por mantener a la masa exacerbada fueron evidentes. ¿Y qué libertad podía esperarse de los representantes si tenían que exponer su argumentación entre el gentío y frente a la misma persona que el ejército había elegido ya como emperador?

El primer diputado en tomar la palabra fue Guridi y Alcocer, el viejo doceañis$t a$, quien a pesar de su apoyo a Iturbide actuó con prudencia y expresó que los poderes de los representantes de la nación eran limitados y no podían aprobar una decisión de tal relevancia sin consultar con sus respectivas provincias, y era preciso legitimar ese paso con el mayor número de apoyos. Una opinión similar fue el manifiesto presentado por José de San Martín, José Ignacio Gutiérrez, Manuel de Terán, José Mariano Anzorena y Francisco Rivas. Pero estas proposiciones fueron desechadas entre el griterío de la población que ocupaba las graderías. Cabe señalar que algunos de los representantes más enfrentados a Iturbide no se encontraban presentes en la sesión, como Carlos Ma. de Bustamante, probablemente por temor a ser arrestados o por miedo a una posible reacción de la multitud.

Posteriormente un grupo de diputados, a instancias de Valentín Gómez Farías, suscribió una proposición a favor de la coronación de Iturbide al considerar anulado el contenido de los Tratados de Córdoba, en los que se invitaba a algún miembro de la monarquía española a reinar en México, al no haber sido reconocida la independencia. ${ }^{70}$ Entre los firmantes

${ }^{70} \mathrm{Ibid}$., sesión extraordinaria del 19 de mayo de 1822. Los diputados que suscribieron la proposición fueron: Valentín Gomez Farías, Pascual Aranda, el conde de Peñasco, José Antonio de Castaños, José encontramos a claros iturbidistas que con anterioridad habían apostado por la implantación de un ejército permanente -Pedro Lanuza, Santiago Alcocer o José $\mathrm{Ma}$. Portugal- pero también diputados como Valentín Gómez Farías y José María Bocanegra, ambos republicanos, que aceptaron lo planteado tal vez por la presión del momento, tal vez porque aún no tenían clara su posición frente a Agustín de Iturbide o porque ésta parecía la solución más adecuada para preservar el orden establecido al incluir la propuesta un llamamiento a Iturbide para que jurase obedecer la Constitución, las leyes, órdenes y cualquier decreto que emanase del Congreso. La posición de algunos de los firmantes cambiaría rápidamente tras algunas decisiones políticas adoptadas en el futuro inmediato por Iturbide. La disolución del Congreso y la detención de algunos diputados impulsaron a los representantes del partido borbonista y republicano a unirse para conseguir el derrocamiento del emperador. Muchos de los firmantes de este decreto serían los prime-

María Cobarrubias, Salvador Porras, Ignacio Izazaga, Bernardo J. Benites, Santiago Alcocer, Martínez de Vea, el marqués de San Juan de Rayas, Lino Fregoso, Ortiz de la Torre, doctor Agustín Iriarte, Antonio Galicia, José Antonio de Andrade, Manuel Sánchez del Villar, José Antonio Aguilar, José María de Abarca, Ramón Martínez de los Ríos, Manuel José cle Zuloaga, Rafael Pérez del Castiilo, Francisco Velasco, José María Ramos Palomera, Argandar, Pedro Lanuza, Juan Miguel Riesgo, Camilo Camacho, Manuel lgnacio del Callejo, José Ignacio Esteva, José María Portugal, José Anselmo de Lara, Bocanegra, Diego Moreno, Luciano de Figueroa, Manuel López Constante, José Rudesindo de Villanueva, José Joaquín de Gấrate, Peon y Maldonado, José Ponce de León, Manuel Flores, Gaspar de Ochoa, Labairu, Pedro Celis, Garza, Martín de Inclán y Antonio J. Valdés. 
ros en aprobar posteriormente la anulación de lo sucedido. Cabe resaltar que entre los firmantes de la propuesta estaban algunos diputados que habían pertenecido a la comisión de guerra que había presentado el proyecto en el que se otorgaba a la milicia la defensa del país. Al parecer son los que discreparon de la decisión mayoritaria, puesto que, por ejemplo, Santiago Alcocer expuso en los debates sus opiniones contrarias a la propuesta de la mayoría de la comisión de guerra a pesar de haber pertenecido a ella.

Los representantes de la nación ratificaron la coronación de Iturbide. El partido iturbidista y el ejército desaprobaron las últimas medidas sancionadas por el Congreso y vieron una salida a la situación encumbrando a Iturbide, hasta convertirlo en emperador. Así, esta facción se aseguró la implantación de una monarquía constitucional y evitó el establecimiento de la república.

La coronación de Agustín I no puso fin a los roces entre éste y el Congreso. El entonces emperador trató de poner freno a la implantación de las milicias retardando el envío del decreto a las provincias, mientras que a su vez el Congreso intentó limitarle el poder y no se le concedió derecho a veto, como hemos visto. Ias públicas discrepancias llegaron a su punto culminante con la detención de algunos de los representantes de la nación acusados de conspirar contra el sistema establecido. La respuesta del Congreso a esta arbitrariedad fue contundente y llevó a Iturbide a optar por disolverlo y formar una Junta Nacional Instituyente que tendría como principal labor la formación de una constitución y de una nueva convocatoria a Cortes.

Esta acción tuvo consecuencias insospechadas para el emperador. La Junta Ins- tituyente careció de legitimidad y ni siquiera obtuvo el consentimiento del resto de las provincias, que no habían celebrado elecciones para elegir a sus miembros. Las provincias, que ya habían mostrado su rechazo al Congreso por su inoperancia y falta de representación proporcional, mostraron su oposición a la situación.

La política centralista de Iturbide, junto con las medidas fiscales aprobadas -como los préstamos forzosos- provocaron un malestar generalizado que fue aprovechado por el general Santa Anna el 1 de diciembre de 1822 , al desconocer al gobierno de Iturbide y exigir la reinstalación del Congreso suprimido. El pronunciamiento desembocó en el Plan de Casa Mata donde fueron reconocidas las autoridades locales y se instó ya no a la reinstalación del Congreso, sino a la formación de uno nuevo donde estuvieran representadas todas las provincias. La adhesión al Plan fue rápida al recoger las ansiadas aspiraciones de los gobiernos de las provincias que vieron reconocido su poder. Se puso de manifiesto, asimismo, que Iturbide sólo ejerciera el control efectivo del ejército permanente acantonado en la capital. Aunque en ningún momento se atentó contra su persona, el resultado del pronunciamiento fue la reinstalación del Congreso y la salida de Iturbide de la capital para garantizar la libertad de deliberación del mismo.

Reinstaurado el Congreso, una de sus primeras actuaciones fue declarar nulos el Plan de Iguala y los Tratados de Córdoba, así como la coronación del emperador por considerarla resultado de la fuerza al tiempo que se creó un nuevo poder ejecutivo. La nueva situación política planteada, con las fuerzas de las provincias, separó a los diputados en nuevas facciones o partidos. 
Los republicanos se dividieron en centralistas y federalistas, uniéndose a la primera facción los diputados monárquicos, mientras que los iturbidistas pasaron mayoritariamente a formar una causa común con los federalistas sin renunciar, algunos de ellos, a defender la figura de Iturbide. ${ }^{71}$

El Congreso, que sólo fue reconocido como convocante de uno nuevo, se negó a aceptar este hecho. Tal testarudez llevó a las provincias a desafiar al gobierno central haciendo uso del sistema defensivo aplicado, es decir, armando a las milicias con el fin de reforzar su poder e influir en el Congreso y en el gobierno central. El miedo a la fragmentación del imperio y la presión de los diputados que defendieron la actuación de sus gobiernos locales empujó al Congreso a aprobar una convocatoria para elegir a uno nuevo. ${ }^{72}$ Mientras las milicias provinciales se convirtieron en la fuerza armada de los respectivos gobiernos locales, el ejército profesional se movilizó a favor del gobierno central y se convirtió en su instrumento para pacificar las provincias, aunque nunca hubo necesidad de un enfrentamiento directo entre ambas fuerzas. $^{73}$

La Constitución de 1824 recogió todas las ordenanzas relativas a las fuerzas armadas durante este primer periodo constitucional e introdujo el establecimiento de un ejército profesional junto con una milicia activa en sus dos vertientes, provincial y local. El ejecutivo creado podía disponer de la milicia provincial en caso de alguna necesidad con el objetivo de garantizar la seguridad interior y exterior. Igualmente podía disponer de la milicia local para pro-

\footnotetext{
${ }^{71}$ Alamán, Historia, 1942, t. v., p. 706.

${ }^{72}$ Ferrer, Formación, 1995, pp. 144-145.

${ }^{73}$ Sordo, "Congreso", 2003, p. 139.
}

teger el orden establecido pero bajo previo permiso del Congreso y en caso de que necesitara de ella fuera de sus estados. ${ }^{74}$ El nuevo estado federal surgido tras el Plan de Casa Mata llevó a la práctica las propuestas presentadas hasta entonces por los diputados del Congreso Constituyente.

\section{BiBLIOGRAFÍA}

-Actas constitucionales mexicanas (1821-1824), UNAM, México, 1980 (edición facsimilar).

-Alamán, Lucas, Historia de Méjico, Jus, México, 1942, t. v.

-Anna, Timothy E., El imperio de Iturbide, Alianza, México, 1991.

-Archer, Christon, El ejército en el México Borbón, 1760-1810, FCE, México, 1983.

-Blanco Valdés, Roberto, Rey, Cortes y fuerza armada en los orígenes de la España liberal, 1808 1823, Siglo XXI, Madrid, 1988.

-Broseta, Salvador et al. (eds.), Las ciudades y la guerra, 1750-1898, Universitat Jaume I, Castellón, 2002.

-Colección de constituciones, en la que va puesta en castellano las de Francia, Bélgica, Portugal, Brasil y Estados Unidos, con la Española de 1812 y su discurso preliminar, Imprenta del Eco del Comercio, Madrid, 1836 (edición facsimilar).

-Cuevas, P. Mariano, El Libertador. Documentos selectos de don Agustín de Iturbide, Patria, México, 1947.

-Chust Calero, Manuel, La cuestión nacional americana en las Cortes de Cádiz, Fundación Instituto de Historia Social/UNAM, Valencia, 1999.

_, "Milicia e independencia en México: de la Nacional a la Cívica, 1812-1827" en Salvador Broseta et al. (eds.), Las ciudades y la guerra, 1750-1898, Universitat Jaume I, Castellón, 2002.

\footnotetext{
${ }^{74}$ Constitución de 1824, artículo 110.
} 
-Dublán, Manuel y José Ma. Lozano, Legislación mexicana de las disposiciones legislativas desde la independencia de la república, Imprenta de Dublán y Lozano, hijos, México, 1876.

-Ferrer Muñoz, Manuel, La formación del Estado nacional en México. El imperio y la república federal 1821-1835, UNAM, México, 1995.

-Gutiérrez Casillas, José, Papeles de D. Agustín de Iturbide. Documentos hallados recientemente, Tradición, México, 1977.

-Jáuregui Frías, Luis A., "Los fundamentos de la política fiscal" en Leonor Ludlow y Jorge Silva Riquer (comps.), Los negocios y las ganancias de la colonia al México moderno, Instituto Mora, México, 1993.

-Ludlow, Leonor, "Elites y finanzas durante la gestación del Estado independiente (18211824)", en José Antonio Serrano Ortega y Luis Jáuregui (eds.), Hacienda y política. Las finanzas y los grupos de poder en la primera república federal mexicana, El Colegio de Michoacán/Instituto Mora, Zamora, 1998. y Jorge Silva Riquer (comps.), Los negocios y las ganancias de la colonia al México moderno, Instituto Mora, México, 1993.

-Marchena Fernández, Juan, Ejército y milicias en el mundo colonial americano, Fundación MAPFRE, Madrid, 1992.

-Mosquera Vázquez, Ángeles, El primer parlamentarismo mexicano, 1821-1822, Universitat Jaume I, Castellón, 2001.
-Ortiz Escamilla, Juan, Guerra y gobierno. Los pueblos y la independencia de México, Universidad de Sevilla, Sevilla, 1997.

_, "Defensa militar, negocios e ideología: Veracruz, 1821-1825" en Salvador Broseta et al. (eds.), Las ciudades y la guerra, 1750-1898, Universitat Jaume I, Castellón, 2002.

-Pérez Garzón, Juan Sisinio, La milicia nacional y revolución burguesa. El prototipo madrileño, 1808-1874, CsIC/Instituto Jerónimo Zurita, Madrid, 1978.

-Serrano Ortega, José Antonio y Luis Jáuregui (eds.), Hacienda y política. Las finanzas y los grupos de poder en la primera república federal mexicana, El Colegio de Michoacán/Instituto Mora, Zamora, 1998.

-Sordo, Reynaldo, "El Congreso Nacional: de la autonomía de las provincias al compromiso federal" en Josefina Zoraida Vázquez (coord.), El establecimiento del federalismo en México (18211827), Colmex, México, 2003.

-Valle Pavón, Guillermina del, "Los empréstitos de fines de la colonia y su permanencia en el gobierno de Iturbide" en José Antonio Serrano Ortega y Luis Jáuregui (eds.), Hacienda y politica. Las finanzas y los grupos de poder en la primera república federal mexicana, El Colegio de Michoacán/Instituto Mora, Zamora, 1998.

-Zoraida, Josefina, "Los primeros tropiezos" en Daniel Cosío Villegas (coord.), Historia general de México, Colmex, México, 1987. 